\title{
ESTABLECIENDO RASTROS
}

PARA LA CONSTITUCIÓN

de una Persona Activa de Derechos:

El Cuerpo de la Violencia

\section{en la Historia de los Montes de María}

Por: Orlando Durango Rueda

Mabel Valencia Mosquera
A los docentes de la Normal Superior de los Montes de María

\section{RESUMEN}

El trabajo rastrea en estos últimos años, el rostro de la violencia en los Montes de María, Bolívar; busca rescatar de estos grupos la historia de su capacidad de darse un territorio y unos imaginarios, que dejen de ser los de la fuerza y de la intimidación, para volverse posibilidad de pensar un espacio, unas relaciones y una cultura, alumbradas por la tolerancia, la confianza y sobre todo por la circulación de la palabra.

Palabras Claves: Persona Activa de Derecho, violencia, silencio, esperanza, identidad.

\section{ABSTRACT}

This work explores the faces of violence durign the most recent years in the Montes de Maria region, located in the colombian department of Bolivar. It seeks to rescue the comunity's historical capacity of appropiating territory and creating an imaginery different to those of force and intimidation, thus enabling them to think a space, a system of social realtions and a culture enlightened by tolerance, trust and above all the free circulation of speech.

Key Words: Active in rights individual, violence, silence, hope, identity.

\section{Introducción}

finales del año 2006, el país merece la lectura del nivel internacional, ejercicio que en ese momento mostraba índices negativos de cara a la - práctica de los Derechos Humanos, que se expresaron en desapariciones, 
muertes violentas, agresiones contra la población civil, desplazamientos y amenazas entre otros, que conformaron la historia de un estado que había pervertido sus controles y sus ofertas sociales para asegurar en la población una convivencia que se asumía sana, por que tenia capacidad de que la cotidianidad ciudadana se viera alumbrada por una cultura que asumía el conflicto de una manera pacífica.

En esas circunstancias, como en otras semejantes, se miró por parte de la dirección política del país, que era necesario recurrir a la educación para auscultar en ella las posibilidades de incidir positivamente en la solución de una problemática que no nos permitía recibir la "confianza" de países del nivel internacional para la inversión financiera.

El Estado, a través del Ministerio de Educación Nacional y en asocio con la Organización de Estados Iberoamericanos, elabora una propuesta piloto para desarrollar en cinco (5) departamentos del país (Bolívar, Córdoba, Guaviare, Huila y Boyacá), con escuelas Normales de esas entidades encargadas de formar a los formadores; un Plan para el Desarrollo de una Cultura para la Educación en Derechos Humanos. Este proceso partió de una lectura de contexto del Departamento de Bolívar que tuviese la posibilidad de incidir desde el modelo pedagógico, las prácticas curriculares y los procesos de evaluación de las Normales en la construcción de experiencias escolares que generaran acciones educativas y ciudadanas. El propósito básico es construir ciudadanías en la lógica de unas prácticas democráticas, que por tanto promueven la participación, la identidad, la inclusión y el respeto por la diferencia. El Proyecto procura así constituir experiencias movidas por un ejercicio que hace de la calidad de vida un hecho mucho más integral y más complejo.

Para la orientación de este proceso en el Departamento de Bolívar, el Ministerio encargó a la Universidad de Cartagena, quien a través de la Facultad de Ciencias Sociales y Educación conformó un colectivo de trabajo del que forman parte la Secretaria de Educación Departamental, ICBF- Seccional Bolívar, Defensoría del Pueblo y Red de Mujeres, con quienes se desarrolló durante el 2007 la iniciativa del Ministerio de la cual el trabajo que presentamos constituye el referente teórico construido para mirar en los Montes de María la forma como la violencia se desplegó con toda su fuerza por este territorio, y, sobre todo, representa un registro de la manera como el ciudadano común, el docente de la escuela, el padre o madre de familia, levantó sus opciones de vida local para constituir esta figura humana que llamamos teóricamente Persona Activa de Derechos.

Hablar de una Persona Activa de Derechos en el ámbito de la educación tiene 
que entenderse básicamente como una apuesta de calidad. Hoy nos invade el debate que intenta hablar del aspecto de la calidad para remitirlo a asuntos de naturaleza meramente tecnológica, en la que el contenido de la acción pedagógica, se desparrama sin contenerse, en un sinnúmero de claves numéricas y de relaciones que terminan remitiéndonos a las ideas de eficiencia y eficacia como lógicas que parecen interesarse solamente por las proporciones entre personas que participan y recursos físicos y materiales que se utilizan.

A diferencia de esa propuesta, que orbita sobre nuestras instituciones para establecer sus dinámicas, hablar de la calidad referida a una Persona Activa de Derechos supone reencontrarse con el ser humano en un movimiento consciente por definirse, establecer sus rumbos y mirar sus eventualidades grupales para rehacer un conjunto de relaciones en un territorio y en un tiempo determinado.

Por esta razón la Persona Activa de Derechos se constituye en un proceso de educación, que es básicamente un reencuentro del ser humano con el territorio de la cultura. Entendemos aquí la cultura no en su sustrato físico o simbólico, tal como la antropología clásica la ha definido, sino como acto fundamental que nos permite el salto en el proceso de humanización. En esta perspectiva, más que de la antropología, estamos más cerca del campo de la educación.

Antes de ser un ejercicio para los Derechos Humanos, la Persona Activa de Derechos es una realidad de naturaleza cultural en el sentido que tiene capacidad de descubrirse como naturaleza que se viene domesticando cada día y que viene dándole los sentidos y significados de su propia esencialidad. En eso la persona se hace individuo, ya que transita en una ruta que le permite descubrirse para poder mirar en su contexto y entorno a otras naturalezas que son él mismo, y es también otra naturaleza distinta y por ello se dirige a ella como su propia corporeidad pero también como evento mediante el cual su espiritualidad se reconoce en un territorio en el que sus pasos son también los pasos de su propia construcción.

Desde el lado de la cultura, la Persona Activa de Derechos tiene la posibilidad de reconstruirse en las relaciones con los otros (as); de allí incorpora un vasto continente de aspectos que la humanidad ha conquistado y los tiene como suyos; en ese integrarse, desde la cultura, incorpora unos lenguajes, dispone de un archivo inmenso de palabras, recupera contextos repletos de arte y artefactos, incorpora costumbres, desarrolla hábitos, propicia sentimientos en un proceso en el que lo natural y lo cultural tienen unas opciones inmensas de asociarse. Esta Persona Activa de Derechos es inicialmente adopción, que resulta de recuperar 
1 MORIN, Edgar. Los siete saberes necesarios para la educación del futuro. Magisterio, pag. 112 lo que la naturaleza tiene dispuesto para ofrecerte como ser humano. En ese entorno produce y circula bienes materiales y simbólicos que le suponen un primer contacto como sujeto terrenal y como portador (a) de relaciones que van nutriendo la idea de un territorio que, asumido, genera las primeras imágenes de territorialidad y las primeras condiciones para descubrirse el ser humano en unas posiciones tanto temporales como espaciales.

En esa territorialidad se genera la opción de reinventar procesos, de domesticar relaciones, de generar dominios, de recambiar relaciones; de un ejercicio que era meramente adopción, por el que hombres y mujeres se dieron a la tarea de reinventar nuevos territorios físicos y de producir nuevos universos simbólicos para descubrirse como "Persona activa" en todo el proceso que le dio como resultado ser también creador de la cultura que lo había creado.

Por lo tanto todos aquellos factores físicos, naturales, sociales y culturales que el ser humano despliega para crecer como especie y ser portador de su propia naturaleza física y simbólica, para ser parte de un grupo que reconoce y que lo reconocen, constituyen una primera instancia en el que la especie hace el tránsito activo de recuperarse como humanidad en un ejercicio permanente con el otro (a), en unas disputas de poderes, en unos acomodamientos de territorios que definen la manera de pensarse, de exigirse y de pensarse y exigir de los otros (a). El derecho es derecho como opción de construir lo humano, como despliegue de espiritualidades, o como bien dijera Edgar Morin, de las necesidades que requerimos para "humanizar la humanidad". ${ }^{1}$

Como Persona Activa de Derechos, los individuos (as) desarrollan sus prácticas en el marco de unas relaciones que las sustentan, de unos contextos socioculturales en donde estas prácticas se expresan y unas herramientas físicas y simbólicas desde las cuales se define una determinada cotidianidad. Esta persona es activa porque lo envuelven unos determinados procesos que forman parte de eventos que surgen en el día a día de sus relaciones; el ejercicio de los Derechos Humanos es práctica cotidiana consciente en que nuestros actos además de satisfactorios físicos o espirituales, promueve condiciones que nos permiten ubicarnos en la escala del desarrollo humano. El ejercicio de los Derechos Humanos no puede entenderse como una práctica exótica de eventos que se llenan de ritualidades de naturaleza celebrativa. Este ejercicio se desenvuelve en la cotidianidad que las personas y los grupos desarrollan; se expresa en el acto político de elegir gobernantes, pero se tiene que mostrar igualmente en el desplazamiento por la calle y en los contactos con nuestra vecindad. El ejercicio de los Derechos Humanos asume la diversidad de la 
condición humana para volverse procesos laborales, acompañamientos técnicos, procesos políticos, sentimientos, visiones, distanciamientos, relacionamientos y acercamientos.

Preferimos acercarnos a esta problemática desde el sistema conceptual de Persona Activa de Derechos y no de sujeto porque precisamente esta ultima categoría forma parte de una unidad de pensamiento que lo aproxima como núcleo binario al otro aspecto del objeto. Desde la particularidad del pensamiento funcionalista, el sujeto constituía unos limites que separaban al individuo de la realidad, esta ultima que terminaba por adquirir la naturaleza de lo otro en tanto que lo otro distante. Así el sujeto y el objeto se intervenían a través de unos límites rígidos que hacían del sujeto un ente exageradamente metafísico y del objeto y la realidad una sustancia altamente fisicalista.

Estos linajes nos impidieron ver con naturalidad la idea de sujeto toda vez que intentamos ver al individuo en su comportamiento físico, espiritual y simbólico y el objeto-naturaleza como materialidad y espiritualidad (de ello nos ocupamos anteriormente cuando hablamos de la cultura), conformando interacciones de materias y de subjetividades que se desarrollan en encuentros de objetividades subjetivadas y de subjetividades que se entienden desde su propia materialidad.

El otro aspecto crítico del uso conceptual de sujeto, tiene que ver con las dificultades lingüísticas para asumir el componente femenino del concepto; la palabra "sujeta" contiene aspectos de naturaleza peyorativa que degradan de la dignidad de las mujeres; en ese sentido nos parece muy poco procedente. A ello también es necesario agregar que la idea de sujeto esta referida al acto de dominio y control en procesos que están por fuera de la consideración que

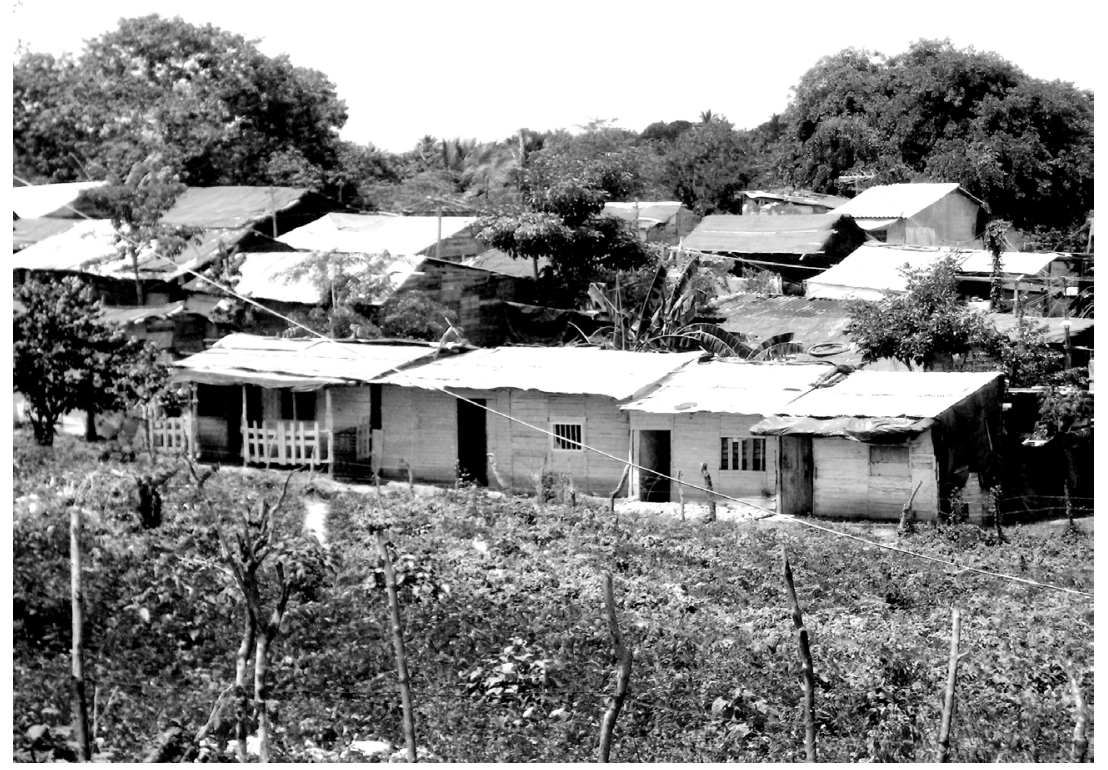
venimos haciendo. Por esta razón hemos preferido acercarnos con la idea de Persona Activa de Derechos, imagen conceptual que nos permite recuperar los vacios que deja la idea de sujeto. 


\section{De Asedios y Violencias en los Montes de María}

Es este contexto humano el que fue asediado por la violencia en el Departamento de Bolívar y en particular en las regiones de los Montes de María y de la Depresión Momposina con cabeceras municipales en San Juan Nepomuceno y Santa Cruz de Mompox, respectivamente. La presencia de la violencia se encargó de resignificar la cotidianidad de tal manera que se trastocaron relaciones, personajes, tiempos de levantarse, tiempos de acostarse.

\section{- Testimonio}

Ahora nos cambió el horario para hacer las cosas que acostumbrábamos; ya no pudimos sentarnos al frente de la casa como acostumbraba la familia a sentarse durante todas las tardes. La leche la tuvimos que comprar en las horas de la tarde porque en las horas de la mañana era muy peligroso ir. Se acabaron las reuniones en las esquinas que usábamos para divertirnos, para pasar el tiempo; inclusive tuvimos que cambiar la hora para ir a misa. (Padre de familia de la normal de San Juan 2007)

En un primer momento la violencia, vuelta fuerza, irrumpe para producir silencios, para recortar la palabra, para producir miedos, para paralizar los cuerpos. Ese fue el impacto primario sobre individuos que vieron desgajarse los cielos sobre sus cabezas en el marco de una polvareda que terminó escondiendo los espantos y borrando los rostros del agresor. ¿Cómo constituir a una Persona Activa de Derechos en esas circunstancias?

Había necesidad de recurrir a la memoria que era aquí menos racional y más práctica. Se sabia exactamente que "no hay mal que dure cien años ni cuerpo que lo resista"; se echó mano entonces de la conciencia como memoria de una situación que tenia que preverse como anómala. No se estaba dispuesto a aceptar que aquella condición de asedio constituía la cotidianidad de los cuerpos. Se hizo conciencia de lo adverso como condición que generaba ciertas posibilidades de prevención, los rostros se endurecieron y los músculos dejaban ver todo el dolor y la rabia. Se hizo silencio a sabiendas de que "en boca cerrada no entra mosca". Lo público se constriñó y el día se acortó; desde lo privado se hicieron reservas para cubrir la familia y en lo privado la palabra, pronunciada de manera tenue, sirvió de vínculo para la comunicación. Allí se hizo el duelo y con el tiempo se pesó la carga. Se tomó distancia, se tomaron prevenciones pero sobre todo esta Persona Activa de Derechos promovió esperanzas y desde allí propició las palabras, quebrantó el asedio y se dio a la tarea de reconstruir lo que la violencia había raptado. Nuevos tiempos y nuevos espacios se soñaron; nuevas relaciones y nuevos lenguajes circundaron las cercanías y lejanías para volverse actos que 
tuvieron las opciones de reemplazo, todo ello vuelto a aplazar cuando nuevamente la violencia asediaba.

Desde la cotidianidad, ser persona Activa de Derechos supone en esta realidad mantener, desde la adversidad, el tipo de país, región y municipio que estamos pensando. La convivencia ciudadana deja de ser un formato establecido que corre por unos senderos que se pueden programar y que se prestan para producir decodificaciones que esperan el tiempo para su desagregación por edades, para hacerse aquí resistencia en el recuerdo y la memoria del territorio invisibilizado.

Lo que se ha perdido o, más bien, lo que los violentos han hurtado es el ciclo de un territorio que se mueve en sus capacidades para producir actos que incorporan como condición la horizontalidad del proceso de comunicación, que a pesar de la estratificación que comportan los sujetos, ella misma se niega a pervertirse para mantener la confianza mínima del habla.

La condición para mantener viva la esperanza es antojarse en un recuerdo, que no es añoranza, si no memoria de la geografía de la ciudad. La cultura que otrora generó las posibilidades para que el colectivo volviera a ubicar la casa en un jolgorio lleno de propósitos de acompañamiento, transporta , vuelto símbolo, aquel lugar de muchos, que lo es, porque sabe contenerlos y albergarlos a todos(as). Mantener el imaginario de la ciudad es contar con la opción de volver a disfrutarla, con sus actores, con sus recuerdos y en no pocos casos, con sus sueños.

Junto a la idea de mantener la posibilidad de recuperar el territorio, no tan sólo por su propia materialidad, sino porque desde la propia cultura es también el diseño de mi propio cuerpo y por tanto de mi propia espiritualidad, la Persona Activa de Derecho le fue necesario aprender a soñar en medio del dolor. No había tiempo de reposar el alma porque aparecía como necesario saber mantener el duelo para levantar desde allí los sueños. El punto de partida ahora no era el reposo sino la urgencia de establecer puntos de llegada donde se pudiera detener el paso. Desde allí la idea del territorio se llenaba de contenidos y se volvía mapas de retorno. Cuando la ciudad se llenó no tuvo que ser ocupada sino asumida en todas sus dimensiones relacionales. El sueño permitió reconstruir la casa de la misma manera que el arquitecto diseña la futura morada. Se había aprendido a mantener la espera a la que se le aprendió a utilizar todas sus medidas de tiempo; de ello también derivaba la posibilidad de sobrevivir y por eso el tiempo se llenó de detalles. Había que aprender a desplazarse con lentitud en una lógica de avance, pero era necesario saber cuando la marcha necesitaba apresurar el paso, casi en un ejercicio de ingeniería de la cotidianidad. 
Parecía que se tenía a la mano un buen número de insumos que permitían el retorno, que no era tan sólo para los que habían salido sino para aquellos que sin perder la morada se encontraban sitiados; a estos nuevos insumos, re-aprendidos en el camino, se recurrió porque era necesario, en el retorno, incorporarle el diálogo a la lógica del silencio. Se había aprendido a hablar con los gestos ya que ellos tenían la virtud de no producir sonidos y eran un antídoto eficaz contra las brujas tierreras. El gesto mantuvo la necesidad de la palabra y a la vez situó al silencio en su justo término. Se trataba de callar para prevenirse de la violencia, pero se procuraba no olvidar que aun el silencio era también una palabra que no se interrumpía y que por tanto se encontraba también lleno de lenguajes que era necesario saber interpretar.

El rostro se volvió un grafito que escribía en todas sus direcciones y el "bembeo" que en otras ocasiones se utilizó para señalar que no se estaba desprevenido, en estas circunstancias movió a la Persona Activa de Derechos para que los labios señalaran direcciones, posiciones, disposiciones, señalamientos, direcciones en un encuentro del rostro con cejas que se arqueaban, con ojos que se abrían y cerraban, con párpados que revoloteaban a la velocidad de las alas del colibrí.

Se trataba entonces del tiempo propicio para empezar a producir la palabra porque el lenguaje nunca se había olvidado, y así como el porro de la sabana se llenó de sonidos, trompetas y clarines sin que las palabras lo acompañasen, pero llenando de lenguajes el cuerpo, el rostro se enervó en una danza que llenó de coqueteos a la vida. La palabra procuró el resquicio y en medio de laberintos creados por caminos que no siempre tenían toda la claridad, se fue produciendo la sonoridad del habla que tuvo la necesidad de crear descansos, en el entorno de la amistad.

Es cierto que la denuncia resquebrajó los blindajes que la amistad había logrado, pero le tocó a la Persona Activa de Derechos buscar en medio de esta orfandad algunos acumulados afectivos y procurar entre los vivos y también entre los muertos un territorio en el que las relaciones, las afectividades, las confianzas, muy maltrechas, tuvieran algún tipo de cobijo.

La amistad y la confianza, esta última que fue el vínculo para que la primera se produjera, echó mano de la familia, que siendo extensa produjo una primera red de confianzas que albergó generaciones y cubrió a varios grupos familiares. La familia fue propicia no sólo porque unió a las personas creando grupos de confianza sino porque tuvo la capacidad que el medio no tenía: la de albergar en su seno fracciones contrarias, que en el contexto de la violencia, terminaban por extinguirse. El afecto soportó las diferencias, le bajó el tenor a la guerra y 
en muchos casos fue el vehículo para que otras redes de familias se encontraran y se prodigaran resguardos.

Cuando el grupo familiar y parental terminó de conformar su incidencia de confianza, las redes ya constituidas hicieron uso de otros recursos culturales para producir cercanías: el compadrazgo estableció líneas de afecto e incrementó el tamaño de las redes, la vecindad fue propicia para dejar sus raíces y procurar nuevos encuentros, los grupos deportivos, los culturales, las relaciones de los y las docentes con los padres y madres de familia, las relaciones de la escuela con los niños y las niñas, las prácticas escolares para crear confianzas, los noviazgos, todos ellos alimentaron el campo de la amistad y la volvieron pedagogía de la confianza y escenario de la palabra.

Había que estirar el cuerpo que la violencia tenía constreñido. ¿Cómo se puede ser abierto (a) en situaciones de asedio? Caminar este trecho era importante sobre todo porque no manejar bien sus límites podría volverte con facilidad objetivo de la violencia, que se había encargado de producir el encierro. No era este un ritual de seguridades pero se convenía con una ritualidad que se había encargado de eliminar lo público, ahora en manos del violento, y la ciudad era tan solo albergues privados de músculos que no tenían posibilidad de movilidad por fuera de la esfera de lo doméstico.

El entorno físico de la casa, semejaba aquellos ritos de duelo en los que la puerta principal de la vivienda se cerraba para darle paso al cuerpo privado del dolor. La alegría se había desalojado para darle paso a aquellos rostros llenos de queja. La luz del sol entraba por las ventanas y las casas tuvieron acceso por la parte trasera. Ya no la sala sino la cocina llenó de tertulias el recinto privado y una vez elaborado el duelo, que la confianza fue procurando agotar las viviendas se mantuvieron cerradas, pero los cuerpos empezaban a abrirse para llenar la memoria de quienes habían salido, para procurar que las voces se llenaran de nuevo de cotidianidad.

Se trataba de volver a hacer lo mismo sin que el cuerpo se paralizara. El ejercicio de aprender a ser abiertos en medio del asedio implicó el incorporar al ciclo del día los tiempos normales de la cotidianidad, haciendo primero asomos que luego se volvieron permanencias que terminaron por reconfigurar lo público. El ejercicio significaba simple y llanamente introducir el cuerpo en la concha de la tortuga y volverla caparazón para que las agresiones del medio tuviesen también posibilidad de tener menos impacto. Y aunque como este animal le tocó muchas veces esconder la cabeza, jamás pensó en doblegar el alma y por eso aquel rostro que no siempre tuvo posibilidad de hacer uso de su mirada, la mantuvo pendiente para volver a asomarlo.

Palobrano. 8 Agosto/2007 
Finalmente, ese grupo humano asediado por la violencia fue muy generoso en elaborar la urdimbre para constituir la esperanza, tuvo que re-aprender el ejercicio de la tolerancia. El aprendizaje en muchos casos fue muy práctico y apareció en situaciones por lo demás simple. Uno de los primeros aspectos que reconstituyó el sentido de tolerancia fue la idea de espera. Durante todo el trecho que caminó al lado de los violentos tuvo la paciencia suficiente para que los sentimientos, las desavenencias, sus contradicciones, sus desaprobaciones se realizaran en el tiempo y el espacio adecuado. Aprendió a esperar estos tiempos y a identificar los espacios que le eran oportunos.

En medio del dolor se descubrió como comunidad que sufre; entendió al otro (a) desde sus propias tensiones, desde sus propias limitaciones, desde sus ansias y desde sus sueños. Cuando todos se encontraron sin nada, el uno requirió del otro (a), se compartieron cosas, se descubrieron diferencias y la casa pequeña, siendo esa la única casa que se tenia, se aprendió al compartirla. Se partía de un mismo principio: el espacio era reducido y los cuerpos deberían poder acomodarse; el más adelantado estableció sus consejas, y cada uno aportó con lo mejor que contenía. Cuando no compartió las posiciones y disposiciones de

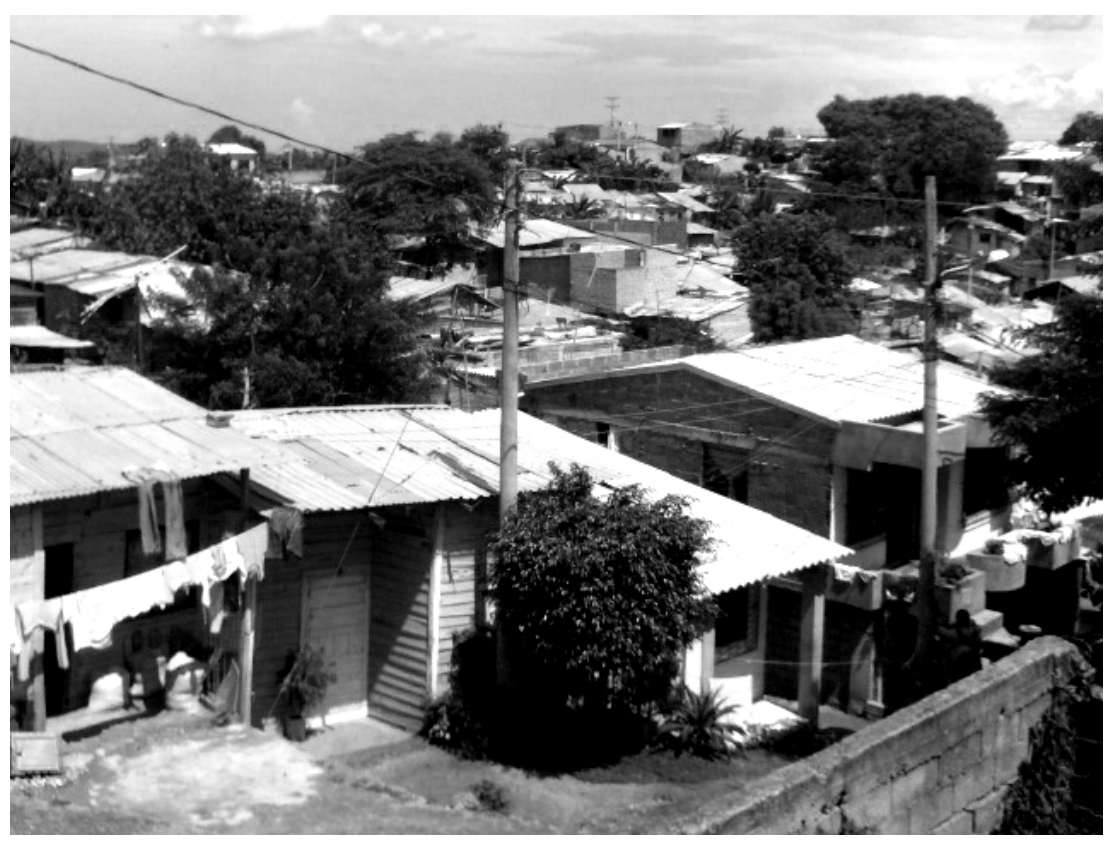

Foto: Nestor Castellar Acosta, Universidad de Cartagena. los otros (as) recuperó el ejercicio de no quedarse callado, nada más que ahora estuvo pendiente del tono. Quería establecer su posición, pero reconocía al otro en la suya.

De este cúmulo de limitaciones sacó ventaja entendiéndose él y entendiendo a los otros; aprendió a no competir, a no procurar ventajas y la tolerancia se incorporó en su cuerpo muchas veces en el ejercicio de acompañar, de buscar junto con el otro en el propósito, casi consciente, de ir estableciendo un acumulado del que podía echar mano en cualquier otro momento. Eso lo había aprendido de su cotidianidad laboral. El trabajo le enseñó a ser solidario, cuando su vecino requirió de su compañía se puso al lado de él y entre juntos hicieron la brega.

El sabía, como dice el dicho que "hoy por ti, mañana por mí". Ese patrimonio lo usó siempre que fue necesario, pero ahora esa practica le sirvió para aprender 
que la tolerancia era un ejercicio fundamentalmente activo y que se construye no sobre la base de soportar al otro (a), sino en acompañar la "milla" al que le requiere y le solicita. Con estos nuevos insumos se estableció la marcha, que no era el movimiento del silencio o de la palabra, sino una realidad que articuló los opuestos y que los volvió unidades de sobrevivencia.

\section{$\checkmark$ Recuperando Cotidianidades desde la Lógica de los Derechos Humanos}

En la constitución de estas circunstancias, la Persona Activa de Derechos conformó una apuesta de formación que bien puede caracterizarse desde cuatro (4) ámbitos problemáticos: el de la convivencia, el de la participación y la responsabilidad democrática, el de las identidades y el de la calidad de vida, territorios que nos han permiten acercarnos a mirar conceptualmente la temática de los Derechos Humanos.

En primer término se volvió actor (a) social, cuando desde un determinado lugar en el contexto, propició acciones tendientes a la producción de convivencias y a la generación de paz. Se es actor (a) social cuando se recupera la capacidad de interactuar, hombres y mujeres, desde sus especificidades y particularidades. Interactuamos cuando aprendemos a abordar comprensiva y críticamente el mundo, que se sabe a todas luces diverso. En ese sentido, el mundo se vuelve diverso cuando corresponde al mundo de lo laboral, al mundo de la familia, al universo de la política, al de la escuela, etc., de donde establecemos el conjunto de redes que nos hacen sentirnos cada vez más especie. Desde el tema de la convivencia, los Derechos Humanos se vuelven capacidad y posibilidad de encuentros y de conversaciones que sin ser homogéneas se hacen importantes porque se sucedieron y produjeron reconocimientos. De allí el tema de la paz que resulta de las necesidades que tiene el ser humano de encontrarse como oportunidad de realizarse aún en el desencuentro, pero en la oportunidad que se da de poder comunicarse. La convivencia se vuelve pacífica, no porque no se altera sino porque recurre al encuentro y al acto comunicativo como hecho fundamentalmente humano.

La interacción como condición que reconstruye lo humano no es un hecho condicionado aunque estas situaciones supongan el ambiente que venimos describiendo; los actos de violencia no intervienen como condicionantes para definir la naturaleza de las relaciones entre los hombres y las mujeres, por mucha fuerza que estas pretendan contener.

Los Derechos Humanos en esta lógica de la convivencia se auto-reafirman como opciones de interlocución en el que lo más importante son las oportunidades que 
los diferentes se dan para convocarse en acciones comunes. Lo que es común es el propósito humano que la actividad entraña y por tanto el tiempo que hombres y mujeres se dan para producir pactos desde la palabra que representan empeños y apuestas para trabajar conjuntamente propósitos que terminamos haciendo comunes.

Así las cosas, lo social adquiere su identidad colectiva en las posibilidades de convocación que se dieron; de allí en adelante el ejercicio está circundado por circunstancias que le confiere a cada uno de los actores(as) su propia especificidad y particularidad. La convivencia es de comunes que saben aceptar y respetar sus diferencias.

En segundo término nos aproximamos al umbral de los Derechos Humanos como actores y actoras políticas en el evento de la participación y la responsabilidad democrática. Lo que los violentos cercenan cuando activan el miedo como recurso o intimidan con el acto de cancelar la palabra, es la realización que tienen los cuerpos en el ejercicio de intervenir; se participa como "conciencia para si" cuando el acto de presencializarnos se descubre como un momento pegado a nuestras condiciones de sobrevivencia como especie; no solo ocurre sino que, como acto consciente, es también un acto provocado que forma parte de las expectativas que nos hemos propuesto. Se participa cuando nos permitimos que el desplazamiento no sólo ocupe nuestras piernas sino que involucre toda nuestra corporeidad. En ese sentido, lo que está en juego mediante la participación es nuestro cuerpo y por ello negociamos en la participación gustos, desplazamientos, sentimientos, sueños, fuerzas, posiciones, representaciones, imaginarios, patrones culturales, escuchas, etc, que constituyen las lógicas de nuestras disputas por bienes materiales y simbólicos así como por representaciones sociales.

Se participa responsablemente, cuando tenemos la capacidad de asumir las implicaciones de nuestros actos sobre todo si en ello no está en juego un juicio moral de lo bueno o lo malo que resultó sino que nos confrontamos con el comprender si nuestra voluntad adquirió la forma de su propio ejercicio. ¿El acto se desarrolló incorporando nuestra voluntad o se sirvió para que otros(as) establecieran sus senderos?

Estos nos parecen los aspectos que la responsabilidad disputa. En su carácter democrático, la participación se vuelve derecho humano porque es siempre inclusiva.

Esta inclusividad es activa porque el "todo" que participa supone diferenciaciones que es necesario tener en cuenta. La totalidad participa democráticamente cuando 
se visibilizan las partes que constituyen el colectivo pero igualmente se reconoce a cada uno en el cuerpo de su propia especificidad. También es conciencia de las exclusiones en la que participamos para establecer sus respectivos correctivos sobre todo si ellas involucran componentes de género, de raza y etnia, de quienes excluimos por sus particularidades físicas o por la manera de definir el uso de su sexualidad. Es siendo inclusivos desde donde la toma de decisiones adquiere su sentido democrático.

Nos parece importante relievar que, si bien es cierto que los signos de violencia que acamparon en estos territorios se dieron a la tarea de eliminar los tiempos y los espacios de participación, reduciendo al mínimo sus posibilidades que se volvieron de índole doméstica, el deterioro de los índices de participación, aunados a su componente de responsabilidad democrática, estos no son el resultado de la violencia acrecentada en nuestras regiones sino que resulta ser una práctica que se venía asumiendo sin que hubiésemos identificado su rostro. Ahora sí se hizo notoria por la fuerza que la violencia desplegaba, pero cuando su ejercicio se realizó echando manos de componentes "tenues", cuando el contexto no era el de la guerra sino el de la escuela o el de la familia se minimizó este proceso de participación que tan solo los actos violentos se encargaron de sacar a flote y mostrar las raíces de su presencia.

En tercer término la Persona Activa de Derechos supone un Ser Social e Histórico que reproduce identidades, desarrolla pluralidades y produce una valoración básica de las diferencias. En un contexto como el nuestro esto constituye un episodio no fácil de recorrer. ¿Por qué? Por que contra la persona, contra su actividad y contra sus derechos, la violencia hace presencia para borrar cada una de estas tres cosas.

Si hay un elemento que siempre estuvo en juego y se convirtió para nuestro poblador (a) en la razón de ser de sus convicciones y terquedades fue el no perder la referencia de la tierra, objetivo de los violentos tanto en su expresión rural como en su asentamiento urbano. El desplazamiento cortó las raíces del tronco y el árbol con sus ramas, movido por el viento y acechado por la calamidad y la rabia, desde las alturas como el águila descubrió donde podía ubicarse temporalmente, aunque muchas veces su estadía se fue consolidando hasta hacerse ciudadano (a) de este nuevo lugar.

Sus reservas culturales las llevó consigo, así como todas sus costumbres y sus imaginarios; perdió la referencia de la tierra, y también todo el universo de sus relaciones que quedaron desparramadas mientras que sus piernas raudas procuraron, inicialmente, no perder la referencia de su territorio. Por eso la 
naturaleza del asedio definió el lugar de su estadía; cuando éste significó un ultimátum que procuraba su desaparición a como diera lugar, el espacio que ocupó se volvió muy distante. La distancia que marcaba su desplazamiento era directamente proporcional a los términos en que estaba elaborado el rumor; muchas veces no tuvo opciones de espera, se trataba de desaparecer en lo inmediato y por esta razón no llevó nada consigo y su carga se redujo tan solo al peso de su propio cuerpo. Se ubicó pensando en los lugares que los flujos migratorios de otros momentos ya habían conquistado; aquí tenía la posibilidad de compartir su indigencia con unos pocos, que en algunos casos le sirvieron de correo de transmisión para que la noticias de su estadía llegaran al lugar de su familia abandonada, presa de la indigencia, lo mismo que sucedía con todo sus enceres, sus labores, sus plantíos, su cosecha y la diversidad de animales que hasta allí se habían cuidado con sumo esmero y que también habían desaparecido como si aquellas voces que amedrentaron su alma, también estos la hubiesen escuchado. Tan sólo "Coronel", perro criollo y muy fiel se había anclado en su casa y en pose de larga espera, machacaba los días que iban pasando sin la compañía de su amo.

En otros casos, los rastros que otros habían dejado no le sirvieron de cobijo y le apuntaron a un pedazo de la familia que peleaba su pobreza en la capital del Departamento, asiento ya de muchos desplazados.

A unos (as) esta estrategia les funcionó, a otros (as) apenas fue una manera de llegar a la nueva casa de los desplazados, para allí empezar a echar raíces de unas identidades que la carrera, el viento y el tiempo habían resquebrajado. Algunas cosas sobrevivieron, otras tuvieron que ponerse a remojo en un hibridismo que saludó a los que con él llegaron para ser también el campamento.

Acá, en la cabecera municipal, la cultura de los lenguajes, las ironías, el cuento vulgar y mal intencionado, entre otras cosas, aunque habían desaparecido, fueron apareciendo como las nuevas hojas de la bonga, después de haber desperdigado la mota en todo el territorio del municipio. El archivo cultural aunque se encontraba cerrado, siempre estuvo dispuesto a mostrarse cuando se lo demandaran. Empezó a expresarse en los grupos de confianza más cercana que casi siempre fue la familia, la cual le permitió jalonar su cotidianidad y reconstruirla, siempre que fuera posible. Los horarios impuestos por el asedio, los territorios prohibidos, los cuerpos contaminantes y las palabras que preguntaban se dejaron de usar y empezaron a aparecer poco a poco. Entre todos se iban dando cuenta de la medida, de lo que era permitido hasta que la cotidianidad fuese llenada con sus costumbres, sus relaciones vueltas a reconstruir.

El volumen de su archivo cultural lo llevaba por dentro y, como la telaraña, 
tenia posibilidad de rehacerse cada vez que el dedo del intruso se posaba sobre ella para destruirla; por eso, desde el ámbito de lo privado empezó a forjar sus nuevas raíces y armar sus nuevos trechos con territorios muy cercanos a los que había visto desaparecer hace muy poco. A su identidad de sabanero o de hombre y mujer anfibios(as) le fue incorporado los cuerpos extraños de la violencia que generó el agresor. A sus depósitos de confianza le tocó incorporar continentes de sospechas; seguía siendo des-complicado(a) y cargaba sobre su rostro mapas y rastros de su alegría pero a pesar de todo no olvidaba el dolor ni desestimaba el duelo.

Como síntesis de lo que cotidianamente había logrado acumular, el cuarto ámbito referido a la calidad de vida, constituye la síntesis de esta experiencia vuelta cuerpo individual y colectivo y convertida en expresión de la cotidianidad. Siente que hoy sus límites culturales, aunque más estrechos, siguen estando intactos aunque introdujo lo que a otros le hubiesen servido para la queja: la solidaridad apareció limitada, la hospitalidad, que se mantuvo, fue tan solo para los suyos; siguió amando el campo y oyendo desde los ríos el desplazamiento del mohán, pero reservó para sí el contenido de aquellos símbolos. Miró a sus hijos, algunas veces lo acompañaron a sus faenas que era realizada con exagerado sigilo y con el tiempo exacto para no gastar un sólo minuto que no fuese necesario. La montaña le sirvió para recordar sus leyendas y el rio con el viaje de sus lanchas le hizo aparecer el tiempo como si por allá no hubiese sucedido nada, aunque sabía que a sus pueblos la violencia los había atravesado para volverlos otra cosa, aunque a fuerzas de intentos sus antiguas identidades se mantuvieran intactas.

Desde antes que la violencia hubiese surcado sus patios y resentido sus músculos y sus sentimientos, cuando empezó a preguntarse por la naturaleza de los otros, situación que lo volvió al territorio de la Persona Activa de Derecho, reconoció la diversidad de los entornos porque sabía que aunque la tierra era diferente porque el espacio donde el palacio municipal se encontraba con la tierra que le servía para producir el pancoger eran distintos; eran distintos los verdes de las montañas porque unos eran mas tenues y otros parecían que el creador había reafirmado el color en ese tramo; los ríos, sobre todo en creciente, parecían una planicie de agua pero eran distintos en los volúmenes de líquidos que conducían, en la cantidad de peces que albergaban, en el color de sus aguas, en las condiciones de su erosión; sus compadres, marido y mujer aunque conformaban una solo familia uno era distinto al otro, casera la mujer, tomador de trago el hombre, habladora su comadre, lleno de silencios su compadre. Todas estas cosas le habían enseñado a entender la pluralidad y también a vivirla. Por eso sabe perfectamente que el efecto de la violencia sobre su sentido innato de la pluralidad fue el quererle hacer ver las cosas, todas ellas, de la misma manera.

Palobrano. 8 Agosto/2007 
La violencia hizo que las montañas perdieran el universo cromado de sus verdes y los ríos ya no fueron distintos, no todos ellos eran corrientes de aguas que desplazaban a sospechosos con intentos de subvertir el orden. La comadre y el compadre dejaron de ser diferentes y se volvieron "mis" delatores y en no pocos casos también fueron los que "me" libraron de una muerte casi segura.

\section{¿Tendremos Chance de Concluir?}

¿Como hacer para volver a recuperar la diversidad? En la realidad es un ejercicio que conjugaba varios tonos; tenía que echar mano de su viejo imaginario para recordar la diferencia de los seres humanos; tenía que alistar su cuerpo para que fuese sensible a la diversidad. Su cotidianidad debía aprender a surcar los distintos niveles y altura, la diversidad de tiempos, el día y la noche, para volver a incorporar lo diverso. Se era distinto y como Persona Activa de Derecho que lo era, lo reconocía, era consiente de esta diversidad, que en muchos casos cuando el agresor tocó a su puerta fue esta diversidad la que lo ayudó a sobrevivir.

\section{BIBLIOGRAFIA}

FOUCAULT, Michel. (1995). Vigilar y Castigar. Siglo XXI, Bogotá. . (2002). Los Anormales. Siglo XXI, Bogotá.

LEVI STRAUSS, Claude. (1998). Antropología Estructural. Siglo XXI, Bogotá.

MORIN, Edgar. (2000) Los Siete Saberes Necesarios para la Educación del Futuro, Magisterio.

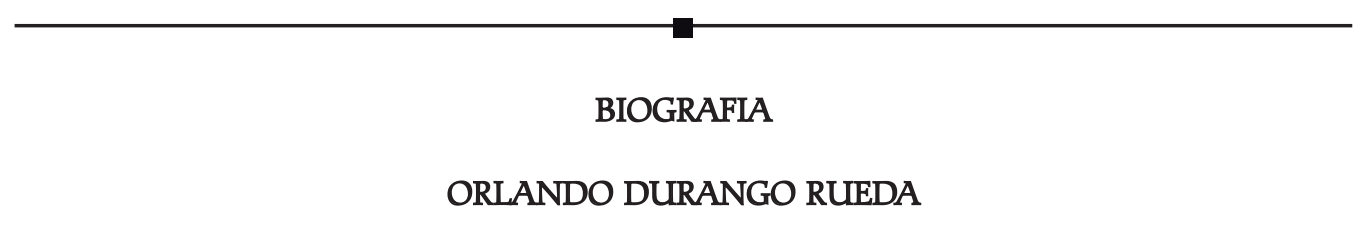

Licenciado en Antropología Social. Escuela Nacional de Antropología e Historia, ENAH. Mèxico, D.F. 1979. Especialista en Gestión de Centros Educativos. Universidad de Cartagena, 1995. Maestría en Ciencias Sociales. Universidad Autónoma de Guerrero, México, 1982

\section{MABEL VALENCIA MOSQUERA}

Psicóloga Universidad de Antioquia. Especialista en Docencia Universitaria, Universidad Santo Tomas sede Cartagena, Especialista en Teorías, Métodos y Técnicas de Investigación Social, Universidad de Cartagena, candidata a Magíster en Estudios de Género, Universidad Nacional de Colombia en convenio con la Universidad de Cartagena, Docente Facultad de Ciencias Sociales y Educación. 